throughout the British socio-economic scale. They are disproportionately represented in jobs of a semi-skilled or unskilled kind. Yet many are in skilled and nonmanual jobs; considerable numbers are in professional occupations, including the medical services not least. Indeed, socio-economic 'polarization' of the various 'new' immigrant groups has been accentuated by the further tightening of immigration restrictions during the last couple of years (Glass, $1965 b$ ).

The new ethnic minorities are thus diverse, not only by origin, language, customs and religion, but diverse, too, by their experience and position in British society. They have in common only the label that is attached to them by virtue of their skin colour, and the handicaps which this label imposes on them at all levels of the society. Their heterogeneity indicates a need for caution in any attempts at generalization about their styles of life--including their food habits.

\title{
REFERENCES
}

Argyle, M. (1958). Religious Behaviour. London: Routledge \& Kegan Paul.

Desai, R. (1 963 ). Indian Immigrants in Britain. London: Oxford University Press.

Glass, R. (1960). Newcomers: the West Indians in London. London: Centre for Urban Studies and Allen \& Unwin.

Glass, R. (1965a). In London's Housing Needs. [R. Glass and J. H. Westergaard.] London: Centre for Urban Studies.

Glass, R. $\left(1_{96} 5^{b}\right)$. The Times, 30 June, I July.

Jackson, J. A. (1963). The Irish in Britain. London: Routledge \& Kegan Paul.

Krausz, E. ( 1964$)$. In fewish Life in Modern Britain. [J. Gould and S. Esh, editors.] London: Routledge \& Kegan Paul.

Lipman, V. D. (1954). Social History of the fews in England, 1850-r950. London: Watts.

Mann, H. (1852-4). Census of Population 1851: Religious Worship. (British Parliamentary Papers, I $852 / 3$, vol. $89 ; 1854$, vol. 59 .)

Mudie-Smith, R. (editor) (1904). The Religious Life of London. London: Hodder \& Stoughton.

Patterson, S. (1964). In London - Aspects of Change. [Centre for Urban Studies, editor.] London: MacGibbon \& Kee.

Prais, S. J. (1964). In fewish Life in Modern Britain. [J. Gould and S. Esh, editors.] London: Routledge \& Kegan Paul.

Rex, J. \& Moore, R. (1967). Race, Community and Conflict. London: Oxford University Press.

Spencer, A. E. C. W. (1966). In The Committed Church. [L. Bright and S. Clements, editors.] London: Darton, Longman and Todd.

Wilson, B. (1966). Religion and Secular Society. London: Watts.

Zubrzycki, J. (1956). Polish Immigrants in Britain. The Hague: Nijhoff.

\section{Social and economic implications of minority food habits}

\section{By J. C. McKenzie, Office of Health Economics, I62 Regent Street, London, $W$ I}

'Minority food habits' is something of an ambiguous phrase and I propose to begin this paper by defining the field which I shall be examining. Several years ago Professor Yudkin and I (Yudkin \& McKenzie, 1964) defined food choice and food habits in the following way:

Food choice- the food selected by an individual at a given time.

Food habits - the sum of the food choice of an individual constituting his total diet. 
In this paper I shall take 'minority food habits' to mean those habits which either in the preparation of food or the type and pattern of consumption of food are so different from those of the community as a whole that this factor is by itself sufficiently distinctive to separate off a group of individuals from the rest of the community.

\section{Classification of groups with minority food habits}

In this country groups with food habits substantially different from the community as a whole are of two distinct types. Firstly, there are those for whom a particular type of diet or preparation of food, or both, is a key aspect of their religion or the philosophy of life to which they adhere. Secondly, there are those immigrants who bring with them the food habits which they practised in their native country.

\section{Religious food laws}

Many religious groups have precise dietary laws. Thus Muslims are forbidden to eat: (I) animals that have died of natural causes, (2) blood, (3) pig's flesh, (4) animals slaughtered as an offering by another religion.

Whilst, traditionally, other foods may be rejected only these four categories are specifically designated by the Koran (2.172-3): 'He has forbidden you only what dies of itself, and blood, and the flesh of swine, and that over which any other [name] than [that of] God has been invoked. Then whoever is driven by necessity, not desiring, nor exceeding the limit, no sin is upon him. Surely God is Forgiving, Merciful'.

Care must also be taken to differentiate designated foods from those which are merely the subject of personal dislikes. 'We have a case on record from the Prophet Muhammad who, while visiting Maymoonah [his wife] was offered the meat of a dhibb [a kind of lizard]. Instead of saying that it was unlawful he merely said, "I do not care much for it". But he did not prevent his companions from eating it if they so liked'. (Jalandhari, I966).

The Jews provide another example of a religious group with detailed regulations about food. The restrictions are not confined to the types of food they may eat.

Meat and milk must not be cooked or eaten together. Consequently, Jewish housewives are told to arrange their kitchens with separate working surfaces for meat and milk foods and keep separate utensils specifically for each of the foods. Animals and poultry must be examined before slaughter to see if they have any imperfections and if any are found they must be rejected. Slaughter itself must be by traditional method which is designed to allow the maximum drainage of blood. Butchers are licensed by a recognized communal authority such as the Board for Shechita and purchase should only be made from shops displaying such a licence. Meat and poultry must also be kashered either by the butcher or housewife (Jewish Marriage Education Council, r966). 'For kashering the following procedure must be adopted: (I) Into your enamel or plastic bucket you should put sufficient fresh cold water to completely cover the meat and/or poultry, meat bones, etc. Leave it soaking for half an hour. (2) At the end of the thirty minutes, remove the meat or poultry, 


\section{Vol. 26 Food habits and nutrition of minority groups in the UK}

etc., and place it on a wooden, plastic, or wire grid which allows free drainage. Leave it to drain for a few minutes, and then sprinkle it with kashering salt on every side. Meat and poultry, etc., should be left in salt for one hour. (3) When the hour has elapsed, wash all surfaces well in cold water three times and then the meat will be ready for use. After kashering, poultry should be scalded and cleaned once more.'

\section{The vegan philosophy}

Some groups do not adopt minority food habits as part of a series of religious tenets; their attitude to food may be the keystone of a particular philosophy, and indeed the only unifying factor holding the group together. Thus members of the Vegan Society may have little in common with each other except their agreement to the principle of the Charter laid down by the Society: 'Veganism is a way of living which excludes all forms of exploitation of, and cruelty to, the animal kingdom, and includes a reverence and compassion for all life. It applies to the practice of living on the products of the plant kingdom to the exclusion of flesh, fish, fowl, eggs, honey, animal milk and its derivatives, and encourages the use of alternatives for all commodities derived wholly or in part from animals. Veganism remembers man's responsibilities to the earth and its resources and seeks to bring about a healthy soil and plant kingdom and a proper use of the materials of the earth'.

As may be seen from this statement veganism embraces a good deal more than just the rejection of consumption of animal products. In a recent study of the Vegan Society, I found that the strict vegan will whenever possible buy clothes and footwear made of synthetic materials rather than animal ones. Similarly over three-quarters of the women in the Society avoid the use of cosmetics which include animal products. Considerable emphasis is also placed upon the use of 'natural' and 'whole' foods. Brown sugar is preferred to white on two counts-brown is regarded as the natural product; white is bleached using bone charcoal. Similarly brown bread is used almost to the exclusion of white because of the belief in its greater nutritional value. Vegans also smoke and drink less than the general population.

Table I. Types of food consumed by vegans (expressed as the percentage of the sample consuming each food)

\begin{tabular}{lrrrr} 
& \multicolumn{2}{c}{ Vegans } & \multicolumn{2}{c}{ Vegetarians* } \\
Tinned food & $8 \mathrm{r}$ & \multicolumn{2}{c}{83} & \\
Frozen food & 37 & & 46 & \\
Sugar: & 85 & & 92 & 84 \\
Brown & & 95 & & 3 \\
White & & 2 & & 13 \\
All & & 3 & & \\
Bread: & 93 & & 98 & 75 \\
Brown & & 71 & & 4 \\
White & & 0 & & 12 \\
Home-made & & 25 & & 7 \\
All & & 4 & &
\end{tabular}

*Full members of the Vegan Society who 'although hoping eventually to give up eating all animal foods, have not yet achieved this end'. 
Table 2. Smoking and drinking amongst vegans (expressed as the percentage of each sample smoking or drinking)

$\begin{array}{lccc}\text { Vegans } & \text { Vegetarians* } & \begin{array}{c}\text { General } \\ \text { population } \uparrow\end{array} \\ \text { Drinkers } & 7 & \text { I4 } & 57 \\ \text { To } & 40 & 50 & 78\end{array}$

* See footnote to Table $\mathrm{r}$.

†Based on a survey of over 4000 interviews conducted on my behalf by Westminster Research Bureau Ltd.

\section{Immigrant food habits}

Both of the groups so far mentioned differ in their motivation from immigrants who continue to eat the types of food which they were eating in their country of origin once they have settled in the United Kingdom. Here there is no major religious or philosophical reason for adhering to what are now minority food habits. The main reason for continuing to eat specific foods is because they like them and have always eaten them. This adherance to traditional food patterns may also provide psychological stability and reassurance during the period of great uncertainty which must develop as people move from one country with all its tradition and culture to a totally different sort of country.

\section{Resistance to change}

There is no doubt that people may modify their food habits over time. Thus Jews, with or without renouncing their faith, may begin to modify their food habits or at least interpret religious edicts less strictly. Similarly, the indigenous community may begin to shop at local delicatessens, dine at Chinese or Indian restaurants, even start cooking 'foreign' dishes. However, we should not overemphasize the speed at which such integration may occur. Indeed, as has been demonstrated earlier in this paper, in some instances existing food habits form such an intrinsic part of the group's existence or have become so personified with their overall philosophy that they are unlikely to be modified even in the very long run. Even immigrant food habits are not very susceptible to change. In 1963 Pamela Mumford and I (McKenzie \& Mumford, 1964) demonstrated that whilst West Indian families coming to this country were quick to start eating some English foods, these were mostly for snacks or subsidiary meals such as breakfast. However, even immigrants of more than 5 years' standing still tended to eat West Indian foods and dishes for their main meals.

Further studies currently being completed by Miss C. Jones and myself (to be published) have confirmed this picture. A study of the Golborne Ward, North Kensington, London has shown that many popular West Indian foods are widely available in local shops and the trend is for international specialist stores to continue to expand the range of West Indian foods sold. We were also able to confirm that length of residence in this country did not materially affect the position. Only in the case of the least available, least convenient and most expensive West Indian food was there a noticeable reduction in purchases by West Indians of long residence. 


\section{Hostility and isolation}

If minority food habits are always slow and sometimes impossible to change, we must be concerned to examine the sort of problems that will emerge from these manifestations. Later papers will examine the nutritional position in some detail. There are, however, some sociological and economic problems that need to be considered.

Perhaps most significant sociologically is the fact that these food habits set the group apart from the community as a whole. In order to understand this fully we should be aware of two sociological phenomena.

Firstly, man is a gregarious animal. Although many of us occasionally have pipe-dreams of spending our life in isolation away from all the pressure of the modern world, there are few of us who would really like to live for long in such a way. Mostly we are prepared to accept that many of our pleasures and interests are dependent upon other people being around. We are in reality intensely involved with the community about us. This involvement is fostered in three distinct ways. Within the community each person comes to feel he has a role to play and this is of importance to the community. He also feels dependent upon the community for the satisfactory development of his own good life and uses it as a refuge from solitude and fears that would accompany individual isolation. Lastly, and perhaps most important, he develops companionship with particular members of the community (McKenzie, 1967). As such it is not surprising that the individual is likely to react with great hostility to anything which he regards as an attack on the intregrity of the community. At best the individual is steadfastly ignored.

Secondly, we are intensely involved emotionally with food. This is partly because it is so vital to our very existence. We are very aware that if we do not eat and drink we are not going to stay alive for very long. Food is also one of the very first means by which we demonstrate our mood and individuality; thus a baby demands food and then perhaps rejects it; it asserts its personality by asking for particular foods and rejecting others. As we grow older, simply because we eat three meals every day, we come to regard ourselves as experts on the subject. In the same way food asserts itself as an integral part of our culture and many social events in our lives take place round the meal-table. Thus we have another clear set of motivations behind the suspicion, hostility and isolation which faces the individual with noticeably different food habits.

The implications are clear. Everybody likes to be an individual and therefore minor modifications of group behaviour are acceptable; thus a person who does not like greens or will not drink coffee or eat the white of an egg is not regarded unfavourably. But people whose food habits are considerably different are frequently going to arouse major emotional responses. Such developments are evident in the case of each of the minority groups I have examined.

The immigrant at work is regarded with suspicion because of the odd, even repulsive-looking foods, in English eyes, that he brings to work for his lunch. Visits to immigrant's homes are discouraged because of the indigenous population's unwillingness to eat different types of foods. This may be one reason why so few 
immigrants have many social contacts with English people (Table 3). Most immigrants also have to share houses with other tenants (Table 4). If it is a house with mixed races the different cooking smells may well cause offence. All these issues influencing the preparation and eating of foods which are unfamiliar to the indigenous population encourage hostility and may lead to the use of phrases such as 'savage' or 'witch-doctor'. It is surprising that social scientists have not been more aware of this factor in racial tension.

Table 3. Social contact between West Indians and English (Davison, 1966)

$\begin{array}{lcc} & \begin{array}{c}\text { Men } \\ (\%)\end{array} & \begin{array}{c}\text { Women } \\ (\%)\end{array} \\ \begin{array}{c}\text { West Indians having any English friends } \\ \text { after } 2 \text { years in this country }\end{array} & 69 & 53 \\ \begin{array}{c}\text { West Indians having been in an English } \\ \text { home after 2 years in this country }\end{array} & 42 & 27\end{array}$

Table 4. Percentage of households in shared dwellings (Davison, 1966)

$\begin{array}{ccccccccc}\begin{array}{c}\text { Head of } \\ \text { household } \\ \text { born in: }\end{array} & \begin{array}{c}\text { Lam- } \\ \text { beth }\end{array} & \begin{array}{c}\text { Newing- } \\ \text { ton }\end{array} & \begin{array}{c}\text { Hack- } \\ \text { ney }\end{array} & \begin{array}{c}\text { Padding- } \\ \text { ton }\end{array} & \begin{array}{c}\text { Dept- } \\ \text { ford }\end{array} & \begin{array}{c}\text { Batter- } \\ \text { sea }\end{array} & \begin{array}{c}\text { Camber- } \\ \text { well }\end{array} & \begin{array}{c}\text { Seven } \\ \text { boroughs }\end{array} \\ \text { England } & 26 & 25 & 44 & 41 & 29 & 36 & \text { I6 } & 30 \\ \text { Jamaica } & 79 & 69 & 89 & 78 & 65 & 72 & 59 & 76 \\ \text { Caribbean } & 77 & 67 & 91 & 87 & 75 & 73 & 66 & 82 \\ \text { India } & \mathbf{3 5} & 57 & 74 & 62 & 37 & 50 & 23 & 52 \\ \text { Pakistan } & 50 & 65 & 63 & 65 & 44 & 45 & 27 & 57 \\ \text { Poland } & 37 & 34 & 47 & 51 & 36 & 61 & 32 & 45 \\ \text { Ireland } & 41 & 48 & 68 & 63 & 36 & 49 & 24 & 50 \\ \text { Cyprus } & 45 & 51 & 72 & 59 & 32 & 45 & 32 & 51\end{array}$

If food is regarded as a key aspect in the practice of a religion it may be used not only to demonstrate the continual observance of the religion in everyday life but also to preserve the unity of the group and exclude the outsider. Thus the group may wish positively to isolate itself. This view is put fairly explicitly in a recent Jewish publication (Jewish Marriage Education Council, 1966): 'There is also a social value implicit in the observance of these laws. There is the common bond which links Jewish communities everywhere more closely together, and then there is the even more intimate factor of the meal-table becoming the centre of family unity, the more so as the dietary laws make it more convenient to eat at home. In this connexion the constant observance of the laws of kashrut helps the Jew, in his social, business, or professional relationships in the world around him, to retain his own distinctiveness.'

'Whenever and wherever the dietary laws cease to be observed, there is the first step towards a weakening of religious restraints, with a consequent drift away from the community. Unfettered social intercourse with non-Jews inevitably brings in its train intermarriage, and intermarriage ultimately means the end of Jewry. The one sure defence against this drift and assimilation is the Jewish home, and there is no substitute for a home in which the domestic observances of Judaism are lovingly maintained.' 
Segregation may occur not only because a group objects to a particular type of food habits or because there is an unwillingness to allow people with a different view into the home. It may also occur simply because people are uncertain of the type of meal they should provide. Thus meat eaters are often reluctant to invite vegans and vegetarians home for a meal because they cannot imagine how they could feed them on what is felt to be a very limited diet. Moreover, they are not even clear about the intricacies of the diet; is normal margarine, chocolate or bread acceptable to the vegan? Often therefore the vegan is cut adrift from society because of his specific views on food. Recent studies I have undertaken also suggest that he does not respond to this isolation in the same way as other minority groups by linking himself with others of the same views. Consequently he can become a very lonely person.

It is also interesting to note that even though a key aspect of the vegan way of life centres around a specific view about food this philosophy either reflects or encourages the growth of a whole series of other attitudes that differ markedly from the community as a whole. Thus he has distinctive opinions upon issues such as vaccination, animal experiments, spiritualism and contraception.

\section{Table 5. Attitude of vegans to certain activities}

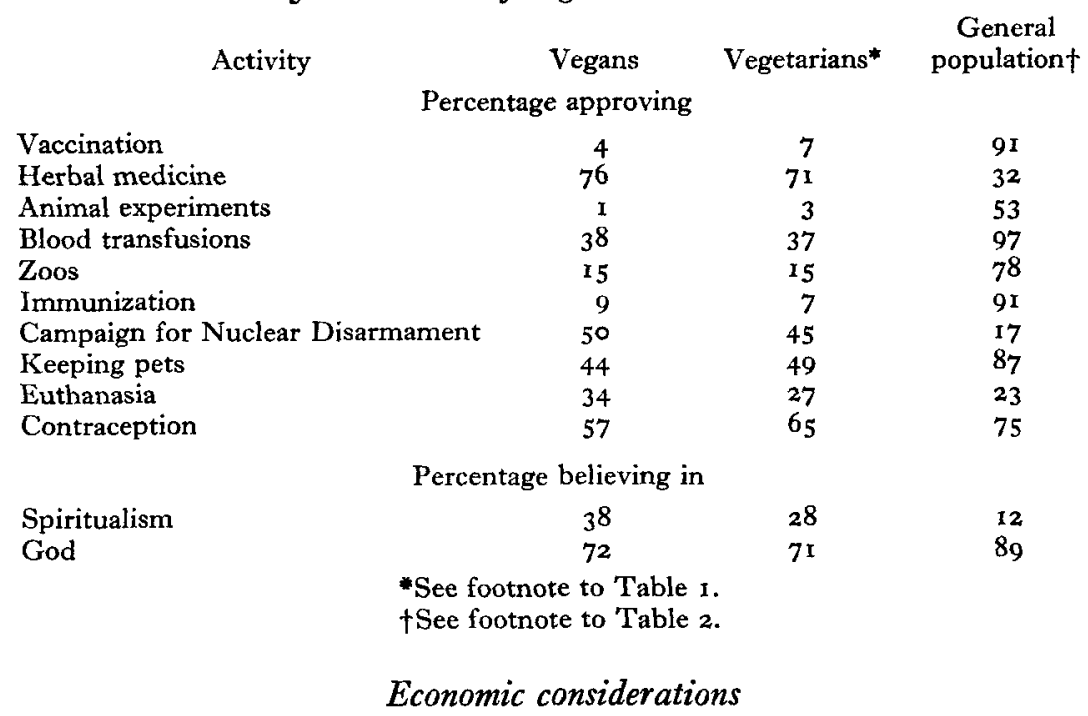

The relative cost of providing a diet different from that of the majority of the population depends on three considerations. These are:

(a) 'The distance of the individual's food habits from the norm. If all the foods demanded are not consumed by other members of the public the cost will be high. However, if certain items available to the public as a whole are acceptable then the minority will receive the benefits accruing from large-scale production.

(b) The size of the minority group. Speciality foods imported or manufactured for a very limited number will clearly be very expensive. Economies will develop as the size of the minority group and hence the market grows. 
(c) The degree of variety which the individual wishes to have within his diet. Miller \& Mumford ( 1966 ) have shown that we could all live on a diet costing $1 /-$ a day provided we were prepared to sacrifice variety and palatability. So too it is likely that any minority group armed with an appropriate set of food tables could find acceptable and adequate food at a cheap price. However, the more they demand a wide range of foods the more likely it is that these will have to be imported or manufactured at high cost.

There is little specific information available on the average cost of diets for different minority groups. It is clear, however, that relatively long-established minorities such as the Jews have a wide variety of services for providing appropriate foods prepared in the correct manner.

Foods common to the West Indies cost a good deal more than their English counterparts. In this country the 'starchy' staple West Indian foods are not cheap by comparison with potatoes. If immigrants are not prepared to change their food habits they will therefore be confronted with two alternatives: they can either spend a greater than normal proportion of their income on food or they can choose a cheaper diet which is likely to be limited both in variety and nutritional value. I believe that most choose the latter alternative with all its implications. This view is based on the evidence that whilst, like for like, West Indian foods are more expensive than English foods in this country, the West Indian spends a smaller proportion of his income on food than English workers in the same wage category.

Table 6. Expenditure on food related to income, country of origin and length of stay (expressed as a percentage of total expenditure) (Davison, 1966; Ministry of Labour, 1963)

\begin{tabular}{|c|c|c|c|}
\hline \multirow[b]{2}{*}{ Weekly wage } & \multicolumn{2}{|c|}{ West Indian } & \multirow[b]{2}{*}{ English } \\
\hline & Ist year in UK & and year in UK & \\
\hline $\begin{array}{c}A^{-}-f_{9} \\
f_{10}-f_{14}\end{array}$ & 34 & 34 & $4 \mathrm{I}$ \\
\hline $\begin{array}{l}\ldots 10-t_{1}, 14 \\
f_{0} 15-f_{0} 19\end{array}$ & $\begin{array}{l}20 \\
27\end{array}$ & $\begin{array}{l}34 \\
21\end{array}$ & $\begin{array}{l}34 \\
33\end{array}$ \\
\hline
\end{tabular}

\section{Conclusion}

Minority food habits may present us with many problems. If some of these are of a nutritional nature we must accept that certainly in the short run, perhaps even in the long run, their solution will not be achieved by advocating major changes in food habits. Nutritionists must look in other directions to deal with any resultant deficiency. Efforts might reasonably include attempts to persuade people to select different, more appropriate combinations of the foods they are already consuming and the addition of nutrient supplements to existing types of dishes. However, the significance of minority food habits goes far beyond nutritional considerations. Food habits are a vital yet almost totally neglected aspect of community integration. Choice of food not only influences our physical health, it also determines our social 'well-being'. 
REFERENCES

Davison, R. B. (1966). Black British. London: Oxford University Press.

Jalandhari, R. A. (1966). The Islamic Review, 54, 5.

Jewish Marriage Education Council (1966). The fewish Home. London: Jewish Marriage Education Council.

McKenzie, J. C. (1967). Proc. int. Congr. Nutr. vir. Hamburg. (In the Press.)

McKenzie, J. C. \& Mumford, P. (1964). Proc. Nutr. Soc. 23, xlii.

Miller, D. S. \& Mumford, P. (1966). In Getting the Most Out of Food, p.9. London: Van den Berghs.

Ministry of Labour (1963). Family Expenditure Survey: Report for 1962. London: H.M. Stationery Office.

Yudkin, J. \& McKenzie, J. C. (1964). Changing Food Habits, London: Macgibbon \& Kee.

\section{The nutritional status of vegans and vegetarians}

By F. R. EluIs, Kingston Group Hospitals, Kingston-upon-Thames, Surrey, and Pamela Mumford, Department of Nutrition, Queen Elizabeth College, London, W8

'There is no disease, bodily or mental, which adoption of vegetable diet and pure water has not infallibly mitigated, wherever the experiment has been fairly tried. Debility is gradually converted into strength, disease into healthfulness . . . the unaccountable irrationalities of illtemper, that make hell of domestic life, into a calm and considerable evenness of temper . . . So wrote the poet Shelley in his pamphlet, $A$ Vindication of Natural Diet, first published in $18 \mathrm{I}_{3}$, from his own experience of 8 months on a vegetable diet. Nutrition would indeed have much to offer mankind if a relatively simple change of dietary regime could be of such benefit to the individual and to society. We wish to examine the present stage of knowledge at least with regard to the adequacy of the diet.

For the purpose of this paper, we shall be considering three groups of people: (I) vegans, whose diet contains no animal foods whatsoever, and who may also refuse to eat vegetable foods in which animal products have been employed for processing-for example, white sugar clarified with bone charcoal, or margarine fortified with vitamin A from animal sources; (2) vegetarians, who eat no meat or fish, but who include milk or eggs, or both, in their diet; and (3) omnivores, who eat an ordinary mixed diet. Since various aspects of the nutrition of vegans and vegetarians were last discussed by the society in the 1950's in symposia on The comparative merits of animal and vegetable foods in nutrition (1951), All flesh is grass (1952) and Vitamin $B_{12}$ (1952), Diet and anaemia (1956) (Nutrition Society, 195 I, 1952,1956 ) there have been a number of dietary surveys of these groups carried out in various parts of the world and some have been reviewed by Hardinge \& Crooks ( $1963 a, b ; 1964)$. These authors concluded that a vegetarian diet meets the nutritional requirements of all age groups, and that vegan diets comprising unrefined cereal products, legumes, nuts, vegetables and fruits produce no detectable deficiency signs. However, they indicated that vegan and vegetarian diets are inadequate if 